\title{
La memoria compartida por las palabras de un transmisor de la historia: Manuel Vázquez Montalbán
}

\author{
ANNE-SOPHIE OWCZARCZAK
}

\section{Planteamiento inicial}

El 20 de noviembre de 1975, Francisco Franco murió después de casi cuarenta años de dictadura. Empezó entonces la transición española encabezada por el nuevo rey de España Juan Carlos I, aunque las bases de aquella nueva etapa política se edificaron durante el tardofranquismo. Durante el proceso transicional, dinamizado por la voluntad de pasar página desde un pasado traumático, aparecieron olas memoriales por una gran parte de la ciudadanía. El "deber de memoria" anhelado por los españoles encontró confrontaciones con el "deber de paz" por parte de la corona española y del nuevo gobierno formado por el rey. El "pacto del olvido" será la línea de conducta promocionada por la Ley de Amnistía de 1977. Desde entonces, y hasta hoy día, la memoria española es polémica. Y lo es porque su gestión es política pero sus raíces son ciudadanas; es polémica puesto que la memoria viene asociada a la verdad, a la historia, a la política, a la pluralidad, al silencio y hasta a la mentira.

Aquel pasado sigue siendo actual. Fue nutrido por movimientos memoriales como la creación de la Asociación para la Recuperación de la Memoria Histórica en 2000 o la promulgación de la Ley de Memoria Histórica en 2007. La memoria "individual" - entendida como la capacidad a recordar o la facultad que uno tiene de registrar y conservar en la memoria periodos, momentos o personas - tiende a ser "colectiva" en España, por compartir recuerdos similares. Pierra Nora afirma que: “"Mémoire' a pris un sens si général et si envahissant qu'il tend à remplacer purement et simplement le mot 'histoire', et à mettre la pratique de l'histoire au service de la mémoire" (Pierra Nora, 2002). Las reivindicaciones memoriales, la dicotomía entre silencio y reconocimiento, la voluntad de una rehabilitación de la voz de los vencidos de la guerra civil en la historia española nos invita a investigar en los archivos.

Queremos investigar en los archivos y, en particular, en un soporte de memoria imprescindible a la hora de investigar el pasado español: en los de la prensa. La prensa española durante la dictadura se dividió en dos: la prensa del gobierno y la prensa de la oposición. Esta última es la que nos interesa si deseamos identificar la memoria silenciada, atrofiada, 
callada: la memoria republicana. Manuel Vázquez Montalbán fue, sin lugar a dudas, una figura emblemática del compromiso español del siglo $\mathrm{XX}$, por su colosal pero también singular obra, por su personalidad y por su estilo de escritura particular y, sobre todo, por su abanico de soportes en los que su escritura permanece más allá del tiempo y de la memoria. La memoria, tanto individual como colectiva, es decir su propia memoria como la de los españoles, es un tema central en la obra montalbaniana, sobre todo desde un enfoque periodístico, el que nos interesa en esta investigación por tres razones. Primero porque Vázquez Montalbán hizo estudios de Filosofías y Letras antes de seguir la carrera en la Escuela Oficial de Periodismo de Madrid en la que inició su carrera con el periodismo. Empezó a redactar sus primeros artículos en 1960 en las revistas El Español y en La Soli, cuando fue reportero de calle. Luego porque Vázquez Montalbán escribió después en los periódicos y en las revistas más famosas de su época como Triunfo, La Calle, Siglo XX, TeleleXprés, Por Favor, El Hermano Lobo, Cuadernos para el diálogo y El País, entre otros. Por fin porque el periodismo no solo fue para él un objetivo profesional sino también personal, porque la prensa fue el soporte idóneo para llegar a las masas, para reivindicar su compromiso personal, cultural, político y personal, para difundir su pensamiento y su memoria.

La prensa del tardofranquismo - de oposición al régimen dictatorialpermitió diseminar una cultura alternativa, crear una conciencia colectiva, entrar en contacto y sensibilizar a los españoles sobre la actualidad. Posibilitó la publicación de una información diferente de la oficial franquista, en nuestro caso, de las informaciones oficiales y del mito político edificado por Franco. A pesar de la Ley de Prensa e Imprenta que entró en vigor el 9 de abril de 1966 -y que engendró una mínima liberalización de la prensa y favoreció una "censura delegada" (Fernández Areal, 1971)- el periodismo se diversificó y adquirió influencia ante un poder político caído en la propia trampa de su censura y luego quebrado tras la muerte del dictador en 1975.

Vázquez Montalbán escribió, entre otras, en dos revistas de oposición al régimen franquista, dos revistas vigiladas por el Ministerio de Información y Turismo (MIT) que regía la prensa española en aquella época: Por Favor (1974-1978) y Triunfo (1946-1982) revista que incluyó la columna La Capilla SiXtina (1970-1978) escrita por Vázquez Montalbán bajo el seudónimo de Sixto Cámara. Vamos a estudiar el contenido de los artículos escritos en estas dos revistas en 1975, este año crucial entre el final de la dictadura y el estreno de la transición, e interrogar el pasado buscando la memoria transmitida por el periodista. Para publicar sus 
artículos desviando la censura que permanecía con la ley de prensa, el periodista tuvo que jugar con las palabras. Las palabras constituían un escudo y un arma contra el poder político. Como decía Vázquez Montalbán: “(...) la réalité extérieure ne te plaît pas, alors tu la reconstruis avec des mots, avec la fragilité des mots" (Vázquez Montalbán, 1977: 20).

En primer lugar, veremos que las palabras escogidas por el periodista nos transmiten no solo su memoria sino también una memoria colectiva española. El vínculo prensa-memoria nos parece incontestable porque el discurso periodístico es un discurso memorial por excelencia. Después, comprobaremos que Vázquez Montalbán no escribió de espaldas a la historia, sino que se enfrentó a ella y se sirvió de ella para hablar del presente. La critica de la actualidad política en 1975 quedó prohibida en la ley de prensa en su artículo 68 y fue considerada como una infracción grave. Por fin, explicaremos por qué las palabras "memoria" e "historia" van a la par en la prensa montalbaniana, creando una pareja que subsana una historia, pero también una memoria censurada.

\section{El método de análisis del corpus}

El corpus, que he escogido, está formado por un total de 89 artículos escritos por Vázquez Montalbán sin colaboraciones, que analizaremos con un método cuantitativo. Si el objetivo es identificar y analizar las palabras utilizadas por el periodista para escribir durante un año tan particular como lo fue 1975, es porque partimos de una constatación lógica: un periodista no escribe de manera aleatoria, ni mucho menos cuando escribe durante un régimen dictatorial. Deseamos entonces analizar las palabras de los artículos mediante un Análisis Automático ${ }^{1}$ que nos permita cuantificar las palabras en relación con nuestro tema y estudiar las relaciones que se establecen entre ellas gracias a los cotextos, es decir todas las palabras que preceden y siguen a la palabra analizada. Este método procura así al investigador los cotextos intralingüísticos, relacionados con el contexto extralingüístico e histórico.

La lexicometría, retomando el término de Maurice Tournier en 1975, lingüista y fundador de la revista Mots. Les langages en politique, se basa en estadísticas realizadas sobre la suma de las palabras de un corpus:

${ }^{1}$ El Análisis Automático es un método de análisis de un corpus de manera científica mediante un programa especializado. 
La lexicometría es una disciplina vinculada a la estadística textual, a la informática y a las ciencias del lenguaje. Es un método de estudio basado sobre el cálculo que permite superar el simple recuento de las palabras, estableciendo, a partir de tratamientos automatizados, las relaciones estadísticas que se producen entre las unidades léxicas. Por consiguiente, la lexicometría abarca toda una serie de métodos que permiten establecer reorganizaciones formales de la secuencia textual, recuentos y comparaciones documentales o estadísticos sobre el vocabulario de un texto o varios textos reunidos y constituidos en corpus. (Pineira-Tresmontant, 1995: 227)

Este método requiere dos momentos. El primero es el descubrimiento de las palabras, de los cotextos, de las relaciones de las palabras entre ellas. El segundo es el análisis de estas palabras tomando en cuenta el contexto histórico, la situación de comunicación y la situación de enunciación - es decir la manera de escribir con la que el hablante pone en escena su discurso - en los que fueron escritas las palabras estudiadas. El programa de análisis que utilizamos es Lexico3, una herramienta de exploraciones textuales que da la posibilidad de estudiar el léxico a partir de un corpus informatizado. Proponemos a continuación una muestra de algunos resultados que forman parte de mi tesis doctoral titulada "L'impact des mots. Approche lexicologique et discursive des articles de Manuel Vázquez Montalbán dans Por Favor et Triunfo en 1975”.

\section{Memoria}

Los artículos de Vázquez Montalbán en Por Favor, Triunfo y La Capilla SiXtina testifican una voluntad de rectificación de la historia española deseada por el periodista en 1975 siempre con estrategias para evitar una lectura detallada del MIT. En el cotexto siguiente realizado a partir de la palabra "memoria" que cuenta con 17 ocurrencias en el corpus -una ocurrencia es el resultado de una palabra que no es considerada como un delimitador, separada en sus extremos por separadores- 7 en Triunfo y 10 en La Capilla SiXtina, el discurso indirecto permite al periodista argumentar su propósito basándose en las voces de otras personas.

No han faltado voces de la España más "oficiosa" que oficial, quejándose de que en nuestras librerías aparezcan publicaciones que glosan distintas facetas de la República y de la guerra civil, vistas desde la perspectiva del vencido. La última palabra histórica, esa palabra definitiva que sanciona los grandes acontecimientos de la vida de la Humanidad, se escribe muchos años des- 
pués, a manera de punto final de una pirámide de palabras, y esa pirámide de palabras, de memoria, de deseo, tienen tanto derecho a construirla los que ganan como los que pierden. (Vázquez Montalbán, Triunfo, 19.07.1975)

El cotexto hace resaltar dos Españas con tres oposiciones: la oficiosa y la oficial; la historia contada por los vencidos, y por oposición implícita, la historia contada por los vencedores que aparece también en el final de la cita "los que ganan como los que pierden". Opone también la historia reciente contra la Historia que está formada por estas historias. El periodista da su punto de vista. Aboga por una historia completa a partir de las experiencias de las personas, las que vivieron la historia que están contando, una historia contada por los que perdieron y los que ganaron la guerra civil. La Historia no puede ser censurada. El periodista aboga por una toma de tiempo para redactar una Historia real, verosímil, sin censura, sin coacciones, sin silencios, como en el ejemplo siguiente. En $\mathrm{La}$ Capilla SiXtina, Vázquez Montalbán escribe el artículo titulado Memoria $o$ Realidad en el que entabla un diálogo con su personaje ficticio Encarna a propósito del pasado:

VM- Tal vez tengas razón. Había por aquí mucho amnésico, y de pronto ha descubierto a Melquiades Álvares, el conde de Romanones, don Alejandro Lerroux, Gil Robles, Marcelino Domingo, Indalecio Prieto...

E- Siga. Siga

VM - No. De momento no se puede seguir. Solo se ha intentado recuperar la memoria hasta Indalecio Prieto.

E - La pena que me da no haber conocido a esos señores...

VM - No te preocupes. Encarna, que ya les conocerás.

E - ¿Reencarnación?

VM - Cada uno de esos hombres significaba la presencia de una fuerza política que representaba una fuerza social, y si ahora o en el futuro esos señores no existieran, habría que inventarlos. Las fuerzas políticas pueden suprimirse por decreto, pero las sociales no. Las fuerzas sociales son esas tenaces raíces de olivo que más tarde o más temprano vuelven a brotar y levantan el olivo donde estuvo.

E - Pero algo debe haber cambiado. A mí, la lista de recuperaciones me parece incompleta, don Sixto. ¿A qué lo atribuye usted?

VM - No lo sé

E - ¿Seguro que no lo sabe? Tal vez la amnesia no esté curada del todo. Tal vez no se haya recuperado del todo la memoria. 
VM - Los "lapsus" establecidos no los atribuiría yo a una insuficiencia de memoria.

E - ¿De qué, entonces?

VM - De sentido de la realidad. (Vázquez Montalbán, La Capilla SiXtina, 26.04.1975)

En este diálogo, Vázquez Montalbán intenta explicar una parte del pasado histórico español no solo a Encarna sino a todos los que no vivieron la guerra civil o a los que no saben realmente lo que pasó en España. El periodista transcribe las emociones de la mujer "la pena que me da..." y las preguntas que pudieran hacerse las generaciones de la post-guerra que intuyen los fallos históricos. Vázquez Montalbán ironiza calificando a ciertas personas de "amnésicas". Unas lo son voluntariamente porque decidieron olvidar, olvidar su propia vida o la de sus familiares, olvidar su identidad, olvidar su infancia. Amnesia, memoria, recuerdos que se mezclan en este diálogo para los lectores a través de la enumeración de personalidades políticas como Melquiades Álvares (1864-1936), político y jurista español durante la Restauración Borbónica; el conde de Romanones (1863-1950) miembro del partido liberal, presidente del Consejo de Ministros y procurador de las Cortes españolas entre 1943 y 1946; Alexandre Lerroux (1864-1949) jefe del partido republicano y del gobierno español entre 1933 y 1935; Gil Robles (1898-1980) jefe de la Confederación Española de los Derechas Autónomas durante la Segunda República y la guerra civil; Marcelino Domingo (1884-1939) periodista y político de la Segunda República e Indalecio Prieto (1883-1962), ministro durante la Segunda República y dirigente del Partido Socialista Obrero Español. Todos tienen un vínculo con la Segunda República y la guerra civil si tomamos en cuenta sus acciones, las fechas, o las circunstancias de sus muertes. Vázquez Montalbán decidió dar un paso atrás, antes de la guerra civil, cuando aún se podía citar a políticos, incluso a los que se oponían a sus ideas. El periodista utiliza la voz del futuro: "ya les conocerás" como si intuyera un cambio futuro en la historia en 1975. "Llegará un día cuando la verdad estalle". La enumeración del ejemplo que se detiene en Franco, nacido en 1892, tendrá una continuación en el futuro: "de momento no se puede seguir". La fuerza argumentativa de este diálogo reside en el silencio final y en los dos interlocutores de dos generaciones, el periodista y Encarna, y en el campo léxico de la memoria que abre la puerta al pasado: "amnésico - recuperar la memoria haber conocido - no existieran - las raíces - la amnesia - los lapsus una insuficiencia de memoria". El papel de la prensa en la transmisión y 
la difusión de la memoria, así como la voluntad de actuar contra el olvido era esencial y Vázquez Montalbán lo sabía. El subterfugio basado en un diálogo ficticio le permite rememorar una memoria colectiva gracias a las palabras que la activan. Cada palabra despierta recuerdos históricos sobre las causas de esta pérdida de memoria: la realidad, la insistencia por parte del gobierno a olvidar, un control de la memoria y del pasado que permanecerá después de la muerte del dictador con la Ley de Amnistía y el pacto del olvido. Vázquez Montalbán utiliza la prensa para oponerse al olvido y sacar a la luz el pasado.

Además, Vázquez Montalbán pone de relieve la sociedad "las fuerzas sociales" en contradicción con la política "las fuerzas políticas". La sociedad, aunque la encierren, se fortalece. Callar a las personas no permite enterrar sus palabras ni sus pensamientos. La prensa es un órgano de difusión del saber, de alternativas, de promoción de una cultura. Hubo durante el tardofranquismo la voluntad de crear una consciencia; de diversificar la prensa y las informaciones que ofrece; de crear una opinión publica eso sí, sin libertad de expresión. Fue una de las directrices de la revista Triunfo: la supremacía de la cultura frente al poder siguiendo las ideas de Antonio Gramsci. Vázquez Montalbán explicaba:

El pensamiento de Gramsci, importante en la formación de la ideología de izquierda en todo el mundo a partir de los años 60, evidentemente ha influido mucho en el contenido y el lenguaje de Triunfo, que compartía, aunque fuera implícitamente, la idea gramsciana de que para llevar a cabo la revolución, hay que acumular saber, un saber crítico orientado hacia el cambio y capaz de oponerse al saber del antagonista. (García Rico, 2002: 177)

Los ejemplos citados más arriba muestran la importancia que tuvo el tema de la memoria en los artículos de Vázquez Montalbán pero sobre todo, nos permiten identificar implícitamente el problema de la censura que padecieron los periodistas, aún más en 1975 cuando los controles y los expedientes aumentaron con León Herrera Esteban, ministro de Información y de Turismo a partir de octubre de 1974. Isabelle Renaudet afirma que "en 1975, la situation fut donc proportionnellement inverse à celle qui, sur une longue durée, fut la plus courante, à savoir la prédominance des sanctions appliquées pour faute légère et $73 \%$ des délits sont considérés comme très graves" y califica la situación como un "attentisme stérile" y de un país "partagé entre le désir d'ouverture et la peur du changement" (Renaudet, 2002: 272-366). Además, sobre 85 expedientes, hubo 15 san- 
ciones muy graves en contra de la moral (Terrón Montero, 1981) estipulada como norma de conducta en el artículo 2 de la ley de prensa. Estas cifras muestran hasta qué punto la historia del pasado y del presente en 1975 estuvo en manos de la política. Vázquez Montalbán, para seguir escribiendo sobre temas tabúes como la memoria o el pasado histórico, utilizó como estrategia la inferencia. Catherine Kerbrat-Orecchioni define la inferencia como "toute proposition implicite que l'on peut extraire d'un énoncé et déduire de son contenu littéral en combinant des informations de statut verbal" (Kerbrat-Orecchioni, 1998: 302). La inferencia es definida también como "(...) un mécanisme général qui consiste à relier de façon déductive un ensemble de prémisses à une conclusion" (Charaudeau and Maingueneau, 2002: 312). En el ejemplo siguiente, Vázquez Montalbán ataca, no de manera indirecta, a Manuel Fraga Iribarne quien redactó la ley de prensa de 1966 - pero no la redactó solo: hubo con anterioridad el Decreto sobre los Medios de Comunicación Social publicado en 1963 (Obispo, 1963) por el Vaticano que, presionó al gobierno español para que adoptara una nueva ley de prensa, abrogando así la de 1938, y luego que influyó en la elaboración del texto jurídico de 1966:

(...) periodistas jóvenes y honestos que buscan la verdad bajo las destrucciones y las conspiraciones de silencio. Es decir, una ciudad viva, un descosido más que demuestra la estrechez del traje superestructural de las Españas, esa estrechez que recientemente ha reconocido el mismísimo Fraga Iribarne. (Vázquez Montalbán, La Capilla SiXtina, 01.03.1975)

En este ejemplo, el valor metafórico de las palabras cobra importancia: "las destrucciones y las conspiraciones de silencio; la estrechez del traje superestructural de las Españas" que permiten una crítica subyacente del gobierno de las Españas, oponiéndose a la juventud, a los periodistas que buscan la verdad. El periodista aspira a una destrucción de esta "ley" de silencio en estas Españas, en plural. El lector de hoy puede interpretar varias posibilidades: ¿existió en 1975 todavía la España de los vencedores y las de los vencidos? ¿Hubo una España conservadora y otra más progresista? ¿Hubo una España a favor de un cambio después de la muerte del dictador y otra a favor de una ruptura? Vázquez Montalbán propone su mensaje con la mención del discurso indirecto retomando las palabras de M. Fraga "que recientemente ha reconocido". El hecho de retomar el propósito del antiguo ministro le libera de una posible sanción del MIT porque si el censor penaliza el propósito del periodista, tendría que hacerlos también con el de M. Fraga. El periodista se sirve de una 
voz intocable para irónicamente criticar al antiguo ministro de Información y Turismo. En efecto, podemos pensar que el periodista pone en tela de juicio la honradez del propósito que retoma en su artículo porque $\mathrm{M}$. Fraga forma parte de los que provocan esta estrechez, política, cultural y jurídica en el país. Ahora bien, la deducción irónica no es posible sin la connivencia del lector que capta y entiende el mensaje, sugerido, del periodista. Esta connivencia apela también la memoria del lector y sus conocimientos. La relación memoria-historia es imprescindible a la hora de entender los artículos de Vázquez Montalbán y su alcance en el pasado, presente, y futuro.

\section{Historia}

Este segundo tiempo permitirá comprobar cómo, a partir de una palabra o de una fecha, Vázquez Montalbán transporta implícitamente al lector en el pasado. En el cotexto siguiente realizado a partir de dos fechas, el periodista escribió a principios del año 1975 el artículo titulado La sequía está contaminada, mediante la ironía marca de la firma de Vázquez Montalbán en la revista Por Favor. Presenta una lista de medidas absurdas tomadas por el gobierno ante la sequía, pervirtiendo las decisiones políticas:

Ante todo han sido detenidos Jaume Perich y Jordi Argente por beber más de cuatro whiskis diarios con exceso de hielo y agua. (...) También se instalarán aparatos especiales en los mingitorios públicos. Cuando la evacuación de orina sea excesiva, sonará un timbre de alarma-denuncia. (...) Sobre la cuestión de la limpieza es posible que se implante la norma de una sola ducha semanal. (...) Quedará gravemente penado el delito de cocinar platos en los que el agua desempeñe una función esencial: potajes, paellas, cocidos, pastas, etc. De seguir la sequía sólo se autorizará la paella el 12 de febrero y el cocido el 18 de julio, es decir, en aquellas fechas señaladísimas del calendario político de la ciudadanía. (Vázquez Montalbán, Por Favor, 20.01.1975)

Vázquez Montalbán parodia las acciones gubernamentales exagerando sus decisiones para remediar las dificultades. La exageración transcribe las restricciones ridículas ordenadas por el gobierno y la censura que persiste en España. Las fechas al final cobran importancia porque muestran la exclusividad de las decisiones en favor de la dictadura. En efecto, todas las medidas citadas deben ser respetadas salvo el 12 de febrero y el 18 de julio, porque son fechas importantes. Vázquez Montalbán no escribe el porqué, deja al lector deducir su mensaje irónico. En realidad, la 
primera fecha marca el discurso de investidura de Arias Navarro el 12 de febrero de 1974 y la segunda es el principio de la guerra civil, el 18 de julio de 1936. El lector, que conoce Vázquez Montalbán, capta la ironía del periodista y su opinión gracias al adverbio "es decir" que marca una pausa. El periodista califica las dos fechas irónicamente de "señaladísimas" y prefiere escribir la fecha antes que el acontecimiento. De nuevo, esta estrategia es posible gracias al lector-cómplice que conoce la revista y reconoce la escritura del periodista. Estas fechas forman parte de la memoria de Vázquez Montalbán pero también de la memoria colectiva española y señala recuerdos en común entre él y los lectores, así como el resto de España.

"España", es la palabra con otras 135 ocurrencias en el corpus (ver anexo), lo que pone de relieve su importancia para el periodista. De hecho, buscamos cómo viene calificada "España" en los artículos en 1975. En Por Favor, la concordancia permite identificar los cotextos siguientes:

"Cada vez que Fraga vuelve a España se le caen las medias a la burguesía..."; "...lo difícil que es caer políticamente en España. Aquí no se cae nunca nadie"; “... un definitivo saneamiento de la España presente y futura sería expulsar del país..."; "la democratización de España ..."; "del progresivo deterioro de España ...."; “...lo difícil que era escribir en España. Últimamente nos han hecho menos caso..."

Vázquez Montalbán, en estos ejemplos, pone de manifiesto su preocupación por la política de España: critica la burguesía española; el callejón sin salida en el que se encuentra la política del país; exagera y critica las expulsiones repetidas en España; escribe a propósito de la democratización del país que, para unos empieza ya antes de la muerte de Franco y para otros, después de 1975. De nuevo subraya la dificultad para los periodistas de poder ejercer su profesión en España. En Triunfo, Vázquez Montalbán califica España de:

"Una España democrática"; "explicar qué significaba escribir en España"; "la situación del subnormal en España"; "la España heroica"; "la España real"; "la España oficial"; "la España laboral"; "el mapa conflictivo de la España que se acerca a los treinta y seis años de paz"; "la España actual"; "la España autárquica". 
Cada adjetivo "democrática, heroica, actual, real, oficial, laboral, autárquica" desplaza al lector a un periodo preciso histórico de manera axiológica: la España de la post-dictadura o de la transición, la España durante la segunda República, la España de 1975 y no mítica, la mítica, la de los trabajadores y por fin la España durante la dictadura. La palabra "España" da acceso a distintos momentos de la historia española. El periodista deja al lector su interpretación.

De nuevo, Vázquez Montalbán en Triunfo, no oculta la dificultad para los intelectuales de poder escribir y ejercer como tales y convoca al mundo mediático que no se encuentra en buenas disposiciones: "explicar qué significaba escribir en España; la situación del subnormal en España". El lenguaje y más precisamente el uso de la palabra está en transformación. El periodista muestra la censura en España utilizando tres verbos "explicar, significaba escribir" a través de una pregunta indirecta. La acción de escribir en España parece tan particular que necesita explicaciones. De la misma manera, el sintagma nominal "la situación del subnormal" describe la situación de los mass media que utilizan un lenguaje "subnormal". Vázquez Montalbán utilizaba este adjetivo para describir la escritura practicada por algunos intelectuales durante el franquismo, como si el sentido estuviera en cautividad. Explicaba: "la presencia de Franco determinaba en buena medida la condición de subnormalidad. Generaba una sensación de estupidez y de subdesarrollo mental" (Tyras, 2003: 59). En España, aún más en 1975, tanto el gobierno como la población están pendientes de un cambio político. El periodo de los irónicos "tres y seis años de paz" terminó pronto y el MIT vigilaba los periódicos - Triunfo padeció ya desde el 6 de diciembre su segunda sanción que forma parte, según el artículo 67 de la ley de prensa, de las más graves, es decir, cierre de cuatro meses de la revista y una multa de 250.000 pesetas - lo que obliga al periodista a autocensurarse, practicando el ya mencionado lenguaje subnormal. Bernard Noël en su obra L'outrage aux mots de 1975 califica esta escritura de "sensure" (Noël, 1975) en francés, en relación con el sentido censurado. En efecto, crea un juego de palabras entre "censure" (censura) y cambia la primera parte de la palabra con otra, "sens" (sentido) para hacer resaltar la falta de sentido.

En La Capilla SiXtina, los cotextos de la palabra "España" no permiten mejorar la imagen del país: "España pasa por uno de los periodos de aislamiento político; inquieta por el futuro de España; la España oficial; la España sensata; España me preocupa" entre otros. Tanto el presente como el futuro del país le inquietan. Muchas veces, Vázquez Montalbán establece paralelismos temporales, para hacer resaltar la preocupación 
por el presente, en relación con el pasado, para aproximarse al futuro. De nuevo los dos adjetivos "sensata y oficial" permiten calificar dos Españas: dos que conviven, la de la población y la del gobierno.

\section{Memoria-Historia}

La memoria es un tema central en el corpus, ya sea cuando Vázquez Montalbán utiliza esta palabra textualmente, o no. La historia, y la recuperación tanto de la historia como de la memoria, cobra importancia a la hora de analizar los artículos. El compromiso montalbaniano en la prensa es perceptible, y sus palabras, como sus estrategias, ponen a la luz la importancia de ver claro el presente y sus dificultades. Hemos visto que una fecha puede rememorar tanto algunos acontecimientos sin escribirlos como también sus silencios. Utilizamos el concepto de "motsévénements", desarrollado por Sophie Moirand. Son: "(...) mots et des expressions qui finissent par devenir le, 'nom' de ces événements" (Moirand, 2007: 56). La memoria es colectiva, y es discursiva, porque la palabra en cuestión activa la memoria del lector: son despertadores memoriales. En la prensa, la relación pasado-presente es evidente dado que el periodista escribe su artículo tomando como punto de referencia el pasado, el vivido por los lectores, y que impacta a toda la sociedad.

En La Capilla SiXtina, Vázquez Montalbán escribe su propio pasado mediante el sintagma "los años triunfales": "Recuerdo a los profesores de Instituto que me examinaban cuando yo me presentaba por lo libre en los años triunfales" (Vázquez Montalbán, La Capilla SiXtina, 05.04.1975). Dando un paso atrás en el pasado, marca una oposición con el presente que no califica de "triunfal". Este sintagma nominal se hace eco del poema de Jaime Gil de Biedma,"Años triunfales" incluido en Moralidades (1966), y que así funciona como un despertador de la memoria para los lectores conocedores de la cultura poética y de la influencia que tuvo Jaime Gil de Biedma en la obra de Vázquez Montalbán. El periodista establece una comparación entre un pasado, aquí triunfal, y un presente que no lo es.

El 17 de febrero en el artículo titulado No hay que Confundir la amnistía con la magnesia, publicado en la revista Por Favor, Vázquez Montalbán retoma el importante término: "amnistía". Juega con las palabras que comparten sonoridades: amnistía, magnesia y amnesia, y argumenta las diferencias semánticas entre estas tres palabras. Y construye una definición propia de amnistía: 
¿Qué es Amnistía? es la ciencia o el arte de que salgan a la calle los condenados por el proceso 1001 y unos cuantos cientos más (esta definición está en estudio por parte de un reducido número de Académicos de la Lengua, en el mejor sentido de la palabra). (Vázquez Montalbán, Por Favor, 17.02.1975)

El acontecimiento bien conocido por los lectores que permite asentar su propósito es el Proceso 1001 que supuso la condena de todos los dirigentes del sindicato Comisiones Obreras, vinculado al Partido Comunista de España, en 1973. En el ejemplo, el complemento entre paréntesis puede ser caracterizado como humorístico si conocemos la situación universitaria en aquella época y la dificultad para definir palabras prohibidas o mal definibles. Es curioso ver que el periodista utiliza el sintagma verbal "salir a la calle" que podría suponer la liberación para los presos. La calle es un símbolo de libertad y un espacio libre.

La Amnistía puede curar a un país de sus grietas pulmonares, estomacales, intestinales, viscerales en definitiva. (...) A todos nos volverían las ganas de vivir y comer, porque la Amnistía la haría todo más apetitoso (...) y es que en definitiva la Amnistía nos alcanzaría a todos porque nada hay tan enclaustrado como una comunidad que mutila parte inexorable de sí misma. (Vázquez Montalbán, Por Favor, 17.02.1975)

A diferencia de la magnesia, la amnistía, según el periodista, tiene efectos a largo plazo. Sujeto y actora principal de la acción en el ejemplo, la amnistía sería para muchos españoles el principio de una nueva era y una liberalización que podría borrar la(s) división(es) entre la población. Sería para el régimen franquista, en cambio, "tolerar" los "delitos" cometidos por los presos, mayoritariamente encerrados porque son comunistas o republicanos, o porque tienen contactos, aunque pocos, con algún miembro del partido comunista, o porque un amigo suyo o un miembro de su familia tiene contactos con este mismo partido, enemigo del poder político, o porque están en contra del régimen. En conclusión, los presos del Proceso 1001 no cometieron ningún delito. El único delito fue ejercer su libertad de opinión, una reivindicación que hace suya el periodista. Vázquez Montalbán muestra la evidente la falta de respeto evidente de los derechos humanos. Las detenciones acarrean rencores entre la población y provocan una espera interminable con la esperanza de que un día sea promulgada la amnistía. La amnistía sería un antídoto para remediar las heridas de la población. 
Los comunistas, y los republicanos, fueron llamados "los rojos", y es una palabra que el periodista utiliza, mayoritariamente en Por Favor 10 ocurrencias contra 1 en La Capilla SiXtina - lo que no parece extraño dado que el humor y sobre todo la ironía son estrategias a las que recurre el periodista. Vázquez Montalbán escribe: "mi plan para un definitivo saneamiento de la España presente y futura sería expulsar del país a todos los rojos" (Vázquez Montalbán, Por Favor, 27.10.1975). El periodista se expresa en primera persona gracias al adjetivo posesivo "mi". Presenta irónicamente una opción: expulsar a todos los que se oponen para que el país sea sano. La frase es irónica y el lector no tarda en darse cuenta, si conoce la ideología del periodista y la de la revista. Se burla indirectamente del poder político. La palabra "rojos" remite a una palabra estigmatizada de manera negativa desde el principio del franquismo, y también remite a la guerra civil y a la persecución, ejecución de los oponentes, y el exilio de los republicanos. Los republicanos fueron considerados hasta el final del franquismo como enemigos del régimen político. Y continúa escribiendo:

¿Quién es rojo y quién no lo es? Yo exigiría a todo ciudadano un certificado de garantía conforme ha celebrado la práctica de los nueve primeros viernes de mes en 1974, un resguardo de la suscripción a Fuerza Nueva y una declaración jurada ante notario de derechas de que solo conecta Radio España Independiente. (Vázquez Montalbán, Por Favor, 27.10.1975)

Vázquez Montalbán crea una parodia alrededor de las decisiones políticas que conducen primero a las expulsiones masivas de los oponentes y ahora a la exigencia de tener un certificado de garantía para mejor interceptar a los "rojos". Este papel de garantía podría ser una maniobra estratégica del periodista para remitir a los arrestos masivos realizados por la policía durante el franquismo para controlar a la población y su identidad. El "yo" - que representa la voz del periodista - vuelve a ser irónica. La ironía es cuestionadora y provoca la reflexión por parte del lector: Vázquez Montalbán hace resaltar lo ridículo del poder, lo que acarrea una toma de conciencia.

\section{Conclusión}

La prensa española, su difusión y su desarrollo después de la Ley de Prensa e Imprenta, representó en aquella época una fuente de información incontestable para los lectores deseosos de leer contenidos diferentes de la prensa del gobierno. Hoy, aquella prensa es una riqueza si uno quiere co- 
nocer la Historia de España desde un prisma íntimo y personal a través de la experiencia de un hombre que rompe el cristal de las prohibiciones a través de la originalidad de un compromiso sin - casi ninguna - restricción. La obra periodística de Vázquez Montalbán es una memoria viva de la España contemporánea y representa una fuente imprescindible para conocerla.

Consideramos los artículos de dicho periodista como un soporte de memoria para todos los que desean leer el pasado escrito por un testigo, para quien el militantismo discursivo tenía como arma "las palabras". No hay duda, las palabras tienen una historia, una memoria, un compromiso, un impacto dado que suenan, resuenan, existen y persisten más allá del tiempo, más allá de toda censura.

Vázquez Montalbán eligió escribir en la prensa porque sabía que sus palabras quedarían intactas y que permanecerían en el tiempo como testimonio, sin los efectos de la memoria. La memoria que difunde en sus artículos es una memoria personal, y colectiva. En sus artículos, Vázquez Montalbán, da la palabra a los vencidos. Afrontando el pasado, rompiendo los tabúes, desviando la censura, manipulando las palabras, propone una memoria alternativa contraria a la memoria institucional, la memoria oficial mítica. Esa memoria auténtica encontrada en la prensa es hoy una fuente relevante para la historiografía que busca contar la Historia.

Vázquez Montalbán tuvo y sigue teniendo, gracias a su obra comprometida, un papel de transmisor de la historia. Si el objetivo de las revistas Por Favor y Triunfo se centraba en la creación de una consciencia colectiva, de la opinión propia de los españoles y de la capacidad de reflexionar, hoy es un buen momento para leer de nuevo estos verdaderos archivos memorísticos, y de parar el olvido para que al fin la Historia sea compuesta por la memoria de los vencedores y la de los vencidos, empezando una renovación historiográfica real. 


\section{Anexo}

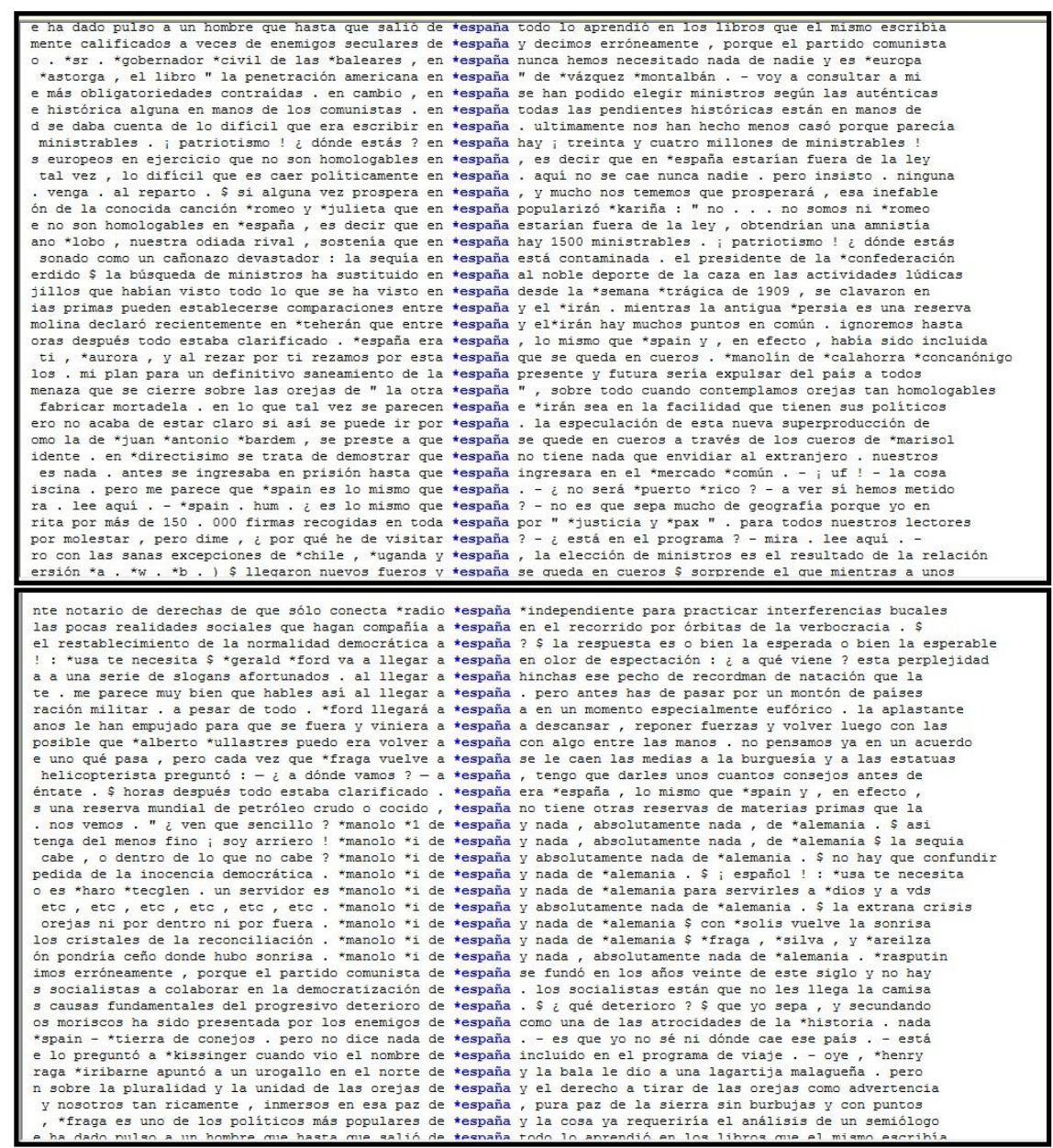

Figura 1: Concordancia de la forma "España" en la revista Por Favor 


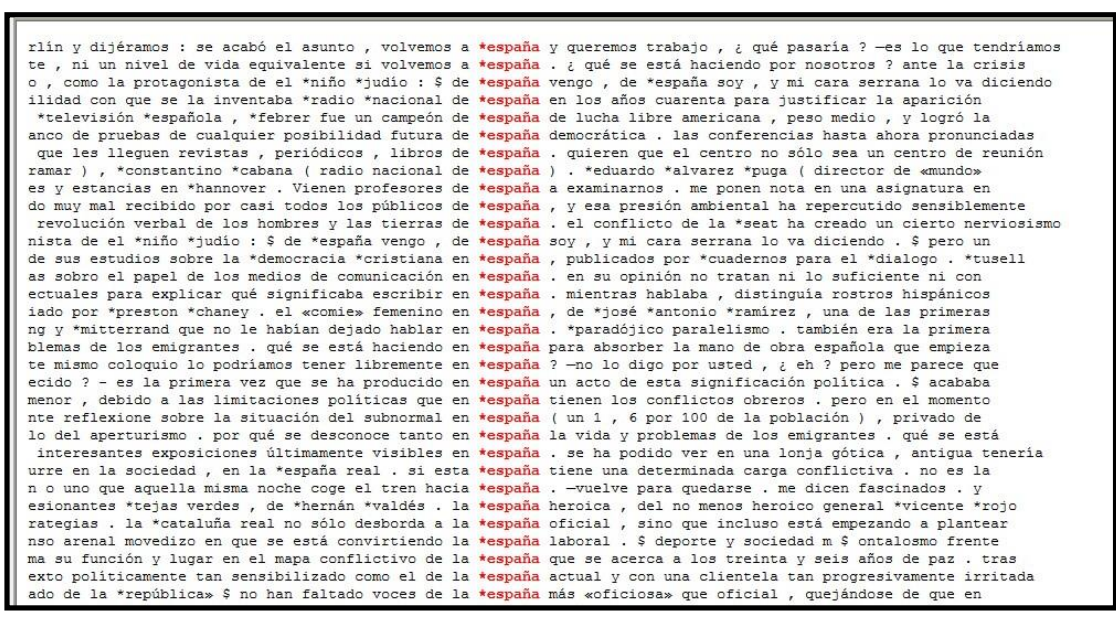

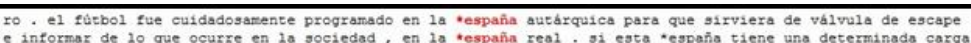

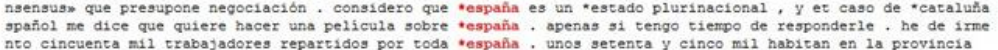

Figura 2: Concordancia de la forma "España" en la revista Triunfo

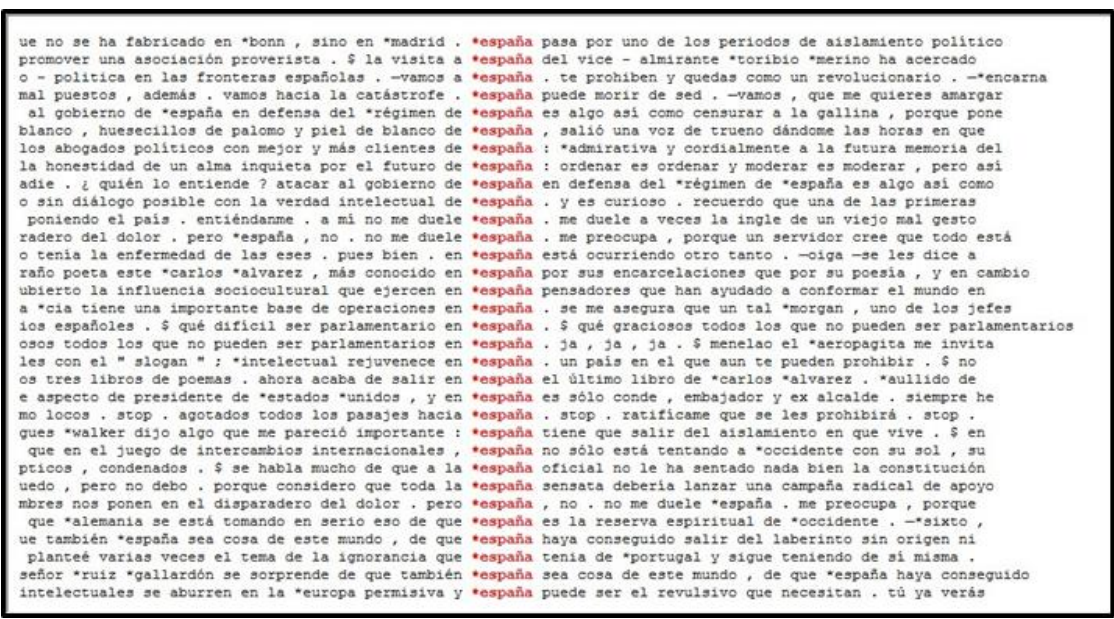

Figura 3: Concordancia de la forma "España” en La Capilla SiXtina, Triunfo 


\section{Bibliografía}

Charaudeau, Patrick, and Maingueneau, Dominique. Dictionnaire d'Analyse du discours. Paris: Seuil, 2002, Impreso.

Fernández, Areal, Manuel. La libertad de prensa en España (1938-71). Cuadernos para el diálogo, 1971. Impreso.

García, Rico, Eduardo. Vida, pasión y muerte de Triunfo. De cómo se apagó aquella voz del progresismo español. Barcelona: Flor del Viento Ediciones, 2002. Impreso.

Noël, Bernard. L'outrage aux mots. Euvre II. Paris: P.O.L Editeur, 2011. Impreso.

Kerbrat-Orecchioni, Catherine. L'implicite. Paris: Armand Colin, 1998. Impreso.

Ley de prensa e Imprenta. Madrid: BOE n67, 1966. [En ligne].

Moirand, Sophie. "Entre discours, langue et mémoire: une analyse de la communication médiatique comme discours verbal et visuel", $H A L$ Archives ouvertes (2017). Web.

Nora, Pierre. "L'avènement mondial de la mémoire", Mémoires d'Indochine, (2002). Web.

Obispo, Pablo. "Decreto sobre los Medios de Comunicación Social", (1963). Web.

Pineira-Tresmontant, Carmen. "Técnicas informáticas de análisis del discurso - Aplicación a textos periodísticos", Manual de Periodismo, (1995): (Chap. IX p. 223-249). Impreso.

Renaudet, Isabelle. Un parlement de papier: la presse d'opposition au franquisme durant la dernière décennie de la dictature et la transition démocratique. Madrid: 2002. Impreso.

Terrón Montero, Javier. La prensa de España durante el régimen de Franco. Un intento de análisis político. Madrid: 1981. Impreso.

Vázquez, Montalbán, Manuel. "La sequía está contaminada", Por Favor, $\mathrm{n}^{\circ} 29,6-7,20.01 .1975$ : Somos europeos.

---. “QQué hacer con los rojos?”, Por Favor, n69, 12-13, 27.10.1975: Que se metan a Raphael donde les quepa.

---. "Un soldado de la República", Triunfo, n668, 19.07.1975: La inflación como respuesta política. Web.

---. "Memoria o realidad", Triunfo, La Capilla SiXtina, n657, 26.04.1975: Hacia una reforma sanitaria en España. Web.

---. "Los PNN de Segunda División”, Triunfo, La Capilla SiXtina, n653, 05.04.1975: Ser mujer, al fin. Web.

---. "A seis kilómetros de Portugal”, Triunfo, La Capilla SiXtina, n648, 01.03.1975: La muerte de García Lorca. Web. 